\title{
Time-Varying Persistence in US Inflation
}

\author{
Massimiliano Caporin * Rangan Gupta ${ }^{\dagger}$
}

This version: October 8, 2014

\begin{abstract}
The persistence property of inflation is an important issue for not only economists, but, especially for central banks, given that the degree of inflation persistence determines the extent to which central banks can control inflation. Further, not only is the level of inflation persistence that is important in economic analyses, but also the question of whether the persistence varies over time, for instance, across business cycle phases, is equally pertinent, since assuming constant persistence across states of the economy, is sure to lead to misguided policy decisions. Against this backdrop, we extend the literature on long-memory models of inflation persistence for the US economy over the monthly period of 1876:2-2014:5, by developing an autoregressive fractionally integrated moving average-generalized autoregressive conditional heteroskedastic (ARFIMA-GARCH) model, with a time-varying memory coefficient which varies across expansions and recessions. In sum, we find that, inflation persistence does vary across recessions and expansions, with it being significantly higher in the former than in the latter. As an aside, we also show that, persistence of inflation volatility however, is higher during expansions than in recessions. Understandably, our results have important policy implications.
\end{abstract}

Keywords: Persistence; US Inflation Rate; Time-Varying Long Memory. J.E.L. codes: C12, C13, C22, C51, E31, E52.

\footnotetext{
*Department of Economics and Management "Marco Fanno ", University of Padova; email: massimiliano.caporin@unipd.it.

${ }^{\dagger}$ Department of Economics, University of Pretoria, Pretoria, 0002, South Africa; email: rangan.gupta@up.ac.za.
} 


\section{Introduction}

The persistence property of inflation is an important issue for not only economists, but, especially for central banks, given that the degree of inflation persistence determines the extent to which central banks can control inflation. Understandably, the amount of research devoted (and still being carried out), given conflicting results $\rrbracket^{1}$ in analyzing the inflation persistence property for the US, as well as, other world economies is voluminous, to say the least. ? $^{2}$ Though various approaches $s^{3}$ have been used to analyze the degree of inflation persistence, autoregressive fractionally integrated moving average (ARFIMA) models is, perhaps, the most popular approach. This is simply because of the fact that the model nests the unit root and stationarity properties of the data, given its generalized form.

Not only is the level of inflation persistence that is important in economic analyses, but also the question of whether the persistence varies over time, for instance being contingent on the state of the economy, is

\footnotetext{
${ }^{1}$ In analyzing the issue of the degree of persistence of the shocks, a related controversy exists concerning the possible existence of a unit root in inflation. On one hand, Nelson and Schwert (1977), Barsky (1987), Ball and Cecchetti (1990), and Brunner and Hess (1993) provide evidence that the U.S. inflation contains a unit root. On the other hand, Hassler and Wolters (1995), Baillie et al.,(1996), Baum et al., (1999), Bos et al., (1999), Baillie et al., (2002), Hsu (2005), Lee (2005), Ajmi et al., (2008) and Hassler and Meller (2014) among others have found evidence that inflation is fractionally integrated, suggesting that the differencing parameter is significantly different from zero and unity

${ }^{2}$ For a detailed survey in this regard, please refer to Balcilar et al., (2014) and Martins and Rodrigues (2014).

${ }^{3}$ The econometric methods have covered various unit root tests, state-spaced-based time-varying) autoregressive models, and more recently quantile regressions-based approaches. For a detailed literature review in this regard, refer to Tillmann and Wolters (2014) and Manzan and Zerom (forthcoming).
} 
equally pertinent. This is because, assuming constant persistence across business cycle phases, is sure to lead to misguided policy decisions (as well as inaccurate forecasts). Against this backdrop, we extend the literature on long-memory models of inflation persistence for the US economy over the monthly period of 1876:2-2014:5, by developing an autoregressive fractionally integrated moving average-generalized autoregressive conditional heteroskedastic (ARFIMA-GARCH) model, with a time-varying memory coefficient $t^{4}$ which varies across expansions and recessions.5 In sum, we find that, inflation persistence does vary across recessions and expansions, with it being significantly higher in the former than in the latter. As an aside, we also show that, persistence of inflation volatility however, is higher during expansions than in recessions. The rest of the paper is organized as follows: Section 2 discusses the data and the model, with Section 3 devoted to the results. Finally, Section 4 concludes with some policy recommendations.

\footnotetext{
${ }^{4}$ For a detailed survey on ARFIMA models with a time-varying long memory coefficient, the reader is referred to Boutahar et al., (2008) and Aloy et al., (2013).

${ }^{5}$ Note that, ever since the work of Granger and Hyung (2000), Diebold and Inoue (2001), and Mikosch and Starica (2004) it is well-known that spurious long memory behavior can be detected in time series known to be theoretically short memory due to structural breaks (for detailed literature review in this regard, refer to Tsay (2008), Tsay and H ä rdle (2008) and Hassler and Meller (2014). In our case, we deal with this issue by assuming that the break dates are known and that we have two regimes in expansions and recessions.
} 


\section{Model and data description}

We compute US Inflation as month-on-month percentage change in the US consumer price index (CPI) covering the monthly period of 1876:1-2014:5. Understandably, the data on inflation rate starts from 1876:2. The data on the CPI is sourced from the Global Financial Database. Note that, the starting and end-points of the sample coincides with the availability of data at monthly frequency at the time of the paper being written. Given our purpose of associating change in persistence with business cycle phases, we also recover the timing of US recessions from the National Bureau of Economic Research (NBER). Table 1 reports the sequence of peaks and troughs on a quarterly basis. As our analyses consider a monthly inflation time series, we set the end of recessions (and similarly of expansions) to the last month of the quarters indicated in Table 1. Figure 1 in the Appendix of the paper plots the month-on-month inflation rate along with the recession dates (indicated by shaded areas).

To motive the need for considering changes in the inflation persistence across business cycle phases, we perform a preliminary analysis. Firstly, in Table 2, we report a descriptive evaluation of the monthly inflation by comparing few indicators over the entire sample, and conditioning on the cycle regime. We note that, over recessions, inflation has a lower mean, and a somewhat higher volatility as compared to expansion periods. However, we also find that the very long inflation time series contains 


\begin{tabular}{|c|c|}
\hline Peak & Through \\
\hline & December 1854 (IV) \\
\hline June 1857(II) & December 1858 (IV) \\
\hline October 1860(III) & June 1861 (III) \\
\hline April 1865(I) & December 1867 (I) \\
\hline June 1869(II) & December 1870 (IV) \\
\hline October 1873(III) & March 1879 (I) \\
\hline March 1882(I) & May 1885 (II) \\
\hline March 1887(II) & April 1888 (I) \\
\hline July 1890(III) & May 1891 (II) \\
\hline January 1893(I) & June 1894 (II) \\
\hline December 1895(IV) & June 1897 (II) \\
\hline June 1899(III) & December 1900 (IV) \\
\hline September 1902(IV) & August 1904 (III) \\
\hline May 1907(II) & June 1908 (II) \\
\hline January 1910(I) & January 1912 (IV) \\
\hline January 1913(I) & December 1914 (IV) \\
\hline August 1918(III) & March 1919 (I) \\
\hline January 1920(I) & July 1921 (III) \\
\hline May 1923(II) & July 1924 (III) \\
\hline October 1926(III) & November 1927 (IV) \\
\hline August 1929(III) & March 1933 (I) \\
\hline May 1937(II) & June 1938 (II) \\
\hline February 1945(I) & October 1945 (IV) \\
\hline November 1948(IV) & October 1949 (IV) \\
\hline July 1953(II) & May 1954 (II) \\
\hline August 1957(III) & April 1958 (II) \\
\hline April 1960(II) & February 1961 (I) \\
\hline December 1969(IV) & November 1970 (IV) \\
\hline November 1973(IV) & March 1975 (I) \\
\hline January 1980(I) & July 1980 (III) \\
\hline July 1981(III) & November 1982 (IV) \\
\hline July 1990(III) & March 1991(I) \\
\hline March 2001(I) & November 2001 (IV) \\
\hline December 2007 (IV) & June 2009 (II) \\
\hline
\end{tabular}

Table 1: Cycle phases (quarter within parenthesis): source NBER www.nber.org/cycles.html. 


\begin{tabular}{lrrrrrr}
\hline & \multicolumn{3}{c}{ Full sample } & \multicolumn{3}{c}{ From 1920 } \\
\hline & All & Exp & Rec & All & Exp & Rec \\
\hline Mean & 0.002 & 0.003 & 0.000 & 0.002 & 0.003 & 0.000 \\
Median & 0.000 & 0.002 & 0.000 & 0.002 & 0.003 & 0.000 \\
St.dev & 0.007 & 0.006 & 0.008 & 0.006 & 0.005 & 0.008 \\
Min & -0.032 & -0.023 & -0.03 & -0.032 & -0.023 & -0.032 \\
Max & 0.057 & 0.057 & 0.030 & 0.057 & 0.057 & 0.030 \\
Q(1\%) & -0.014 & -0.013 & -0.021 & -0.015 & -0.008 & -0.022 \\
Q(99\%) & 0.021 & 0.022 & 0.019 & 0.018 & 0.019 & 0.015 \\
Skew & 36.379 & 32.199 & 20.908 & 0.308 & 1.931 & -0.604 \\
Kurt & 1427 & 1083 & 450 & 10.29 & 18.69 & 1.51 \\
IQ-range & 0.005 & 0.005 & 0.006 & 0.005 & 0.005 & 0.011 \\
N. zeros & 606 & 403 & 203 & 261 & 215 & 46 \\
N. obs. & 1660 & 1183 & 477 & 1133 & 244 & 891 \\
\hline
\end{tabular}

Table 2: Descriptive analyses

a large amount of zeros, that is periods with a flat price index. Those are concentrated in the first 40 years. Therefore, beside the full sample analyses, we also provide evidences on a shorter sample, starting in January 1920.

We find a confirmation of the full sample results: the average inflation is lower during recessions, while the volatility is higher. Notably, the presence of a large number of zeros has a relevant impact on asymmetry and kurtosis: their level is far more reasonable when we focus on data from 1920. On those reduced sample, we note that inflation is skewed to the left during recessions, and to the right on expansions. This suggest that extreme values drive the mean and variance outcomes, given that during recessions we have instances of drops in inflation (monthly inflation) 
while during expansions we observe large inflation values. Notably, the inflation density is more leptokurtic during expansions, signaling a higher probability of observing extreme inflation movements.

The long inflation time series we consider has not been seasonally adjusted. To verify the need of such an adjustment, we checked by means of the TRAMO-SEATS package. We found no evidences of seasonal patterns on overlapping subsamples of 50 years. We thus proceed on the analyses using the raw data.

If changes in the persistence were present, one way of getting evidences is through the computation of the autocorrelation function conditional to the state of the economy. Mimicking Caporin and Pres (2013) we consider the following estimators of the autocorrelation at lag $k$

$$
\begin{gathered}
\rho_{R}(k)=\frac{\frac{1}{T_{R}-k} \sum_{j=k+1}^{T} x_{t} x_{t-1} S_{t}}{\frac{1}{T_{R}-k} \sum_{j=k+1}^{T} x_{t}^{2} S_{t}} \\
\rho_{E}(k)=\frac{\frac{1}{T_{E}-k} \sum_{j=k+1}^{T} x_{t} x_{t-1}\left(1-S_{t}\right)}{\frac{1}{T_{R}-k} \sum_{j=k+1}^{T} x_{t}^{2}\left(1-S_{t}\right)}
\end{gathered}
$$

where $x_{t}$ is the month $t$ inflation rate in deviation from the sample mean, $R$ stands for recession and $E$ for expansion, $S_{t}$ is an indicator function assuming value 1 during recessions, $T$ is the total sample size, $T_{R}$ is the number of months associated with a recession $\left(\sum_{j=1}^{T} S_{t}=T_{R}\right)$, and $T_{E}$ is the number of months where the economy is in expansion, $T_{E}=T-T_{R}$.

Figures 1 and 2 report the autocorrelations computed with the standard 


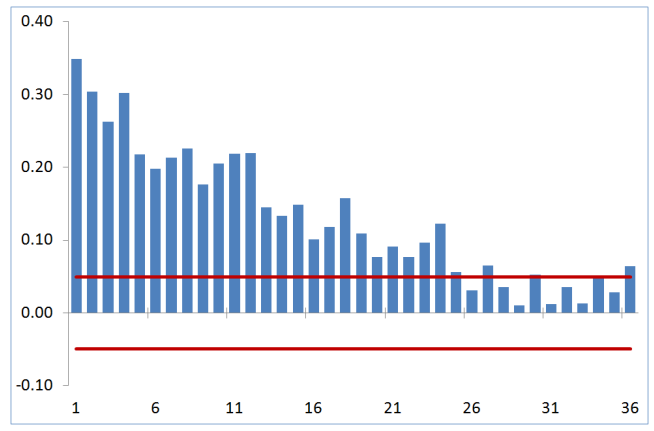

(a) Full sample ACF

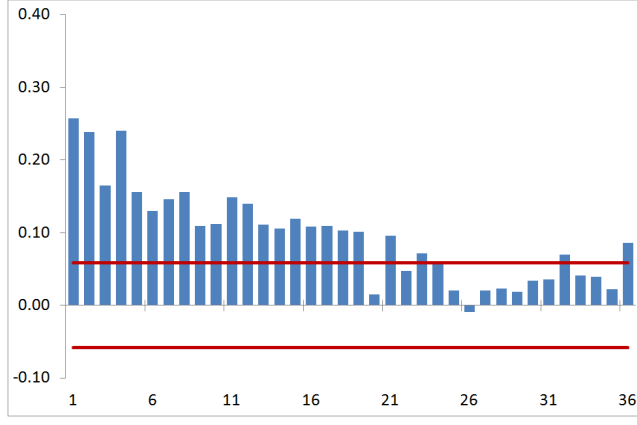

(b) Expansion ACF

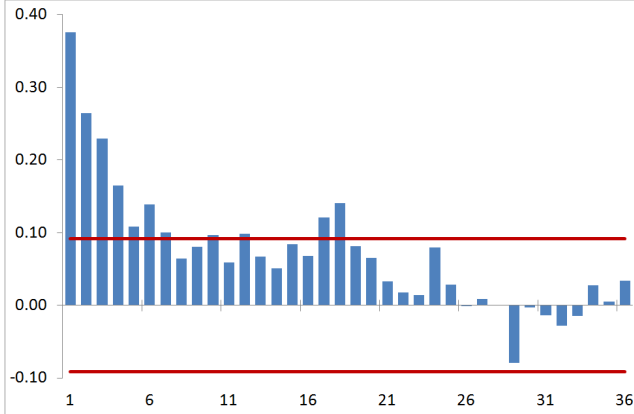

(c) Recession ACF

Figure 1: Autocorrelation functions (ACF) for the full sample (from 1876) computed with the classic estimator and by conditioning on the cycle phase.

estimator, and by conditioning on the economy state, for both the full sample data (from 1876) as well as by restricting the sample from 1920. Notably, we have evidences of changes in the persistence over cycle phases, but also over time. In fact, while by looking at data from 1876 we note a decrease in the persistence during recessions, the opposite effect, an increase in persistence during recessions, is observed if we start the analysis in 1920. We relate such a change to the large amount of zeros included in 


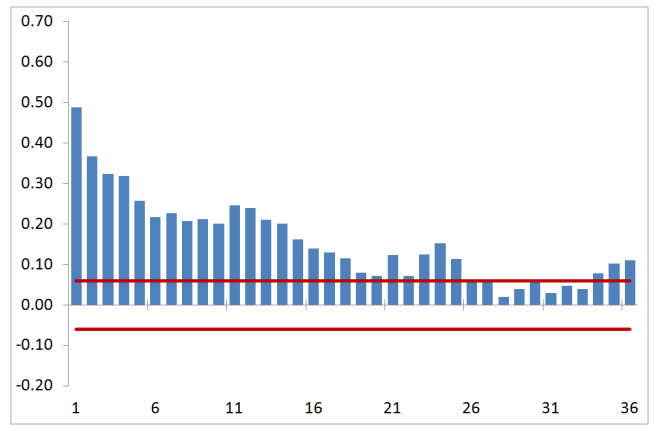

(a) Full sample ACF

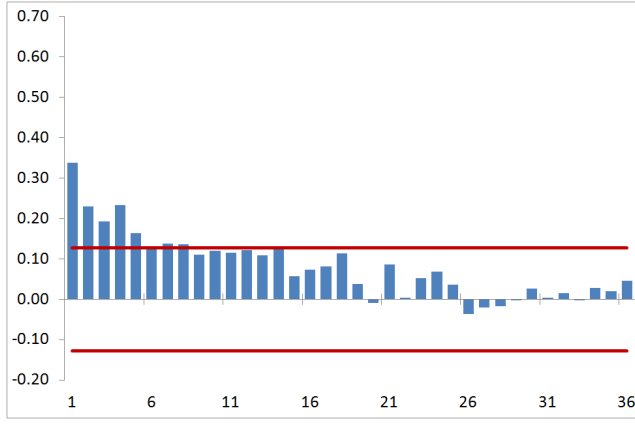

(b) Expansion ACF

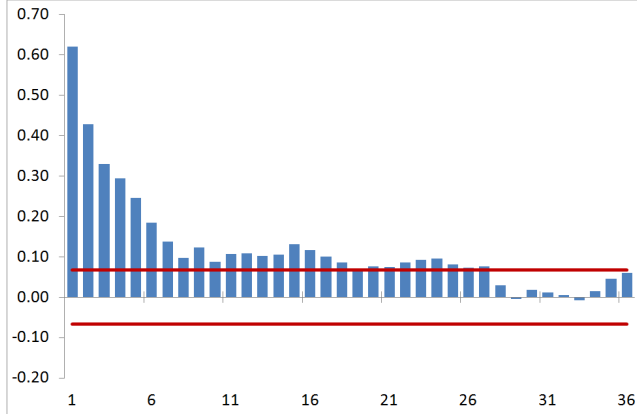

(c) Recession ACF

Figure 2: Autocorrelation functions (ACF) for the restricted sample (from 1920) computed with the classic estimator and by conditioning on the cycle phase.

the time series in the first 40 years. As a result, we believe that Figure 2 plots are closer to the true series behavior. The plots suggest that the inflation time series might be characterized by a mild long-memory behavior. In fact, the persistence is clear but not so strong as we might observe in the presence of long-memory. Nevertheless, the observed autocorrelation patterns could be associated with persistent short-memory processes.

To shed some light on the possible presence of long-memory and, at the 
same time, allow for a change in the persistence across economy states, we suggest to model the CPI growth rates as in Caporin and Pres (2013). Let $y_{t}$ be the CPI growth, or inflation rate, we model it as follows

$$
(1-L)^{d_{t}} \Phi(L)\left(y_{t}-\mu\right)=\Theta(L) \varepsilon_{t}
$$

where $d_{t}$ is a time varying memory coefficient, $\mu$ is the unconditional mean of the inflation, $\Phi(L)$ is an Auto Regressive polynomial, $\Theta(L)$ is a Moving Average polynomial, $\varepsilon_{t}$ is the inflation shock which we assume to be identically and independently distributed with zero mean and variance $\sigma_{\varepsilon}$. The change in the memory coefficients has a step-wise evolution over time according to the change of the business cycle phase. As a consequence, there will be two different degrees of persistence over recession and expansion.

Given that the change in persistence varies according to an exogenous variable, and is thus not exactly a function of the time, the TVARFIMA model of Caporin and Pres (2013) becomes similar to the Threshold ARFIMA (TARFIMA) of Goldman et al. (2013); it differs from the TARFIMA model since the regime change is not associated with the level of the dependent variable (the CPI growth), as it happens in dynamic models with threshold-driven regimes; on the contrary, the change in the parameter structure depends on an exogenous variable, the dummy capturing recessions. The model might thus be compared to the approach of Haldrup and 
Nielsen $(2006 \mathrm{a}, \mathrm{b})$, and thus claimed to be equivalent to a Markov switching model where regimes are known.

In order to capture the possible presence of heteroskedasticity, the model is extended by allowing the error variance to change over time according to the TVFIGARCH model of Caporin and Pres (2009). Therefore, the inflation shocks variance will be denoted as $\sigma_{t}$ and will evolve as

$$
\sigma_{t}^{2}=\omega+\beta(L) \sigma_{t-1}^{2}+\left[1-\beta(L)-\Psi(L)(1-L)^{\lambda_{t}}\right] \varepsilon_{t}^{2}
$$

where $\beta(L)$ and $\Psi(L)$ are short-memory polynomials and $\lambda_{t}$ is the variance memory parameter that changes over time according to the business cycle phases.

Model estimation is performed by maximum likelihood methods, which are shown in Caporin and Pres (2013) to have appropriate asymptotic densities by means of Monte Carlo methods.

\section{Persistence in US inflation}

We fit the TVARFIMA-TVFIGARCH on the inflation time series both on the full sample as well as by restricting the analysis from 1920. Table 3 reports the estimated coefficients and we stress that the memory parameters are always statistically significant. Our empirical results suggests that the inflation persistence is changing across business cycle phases, and is higher during recessions. In fact, and focusing on the full sample results, 


\begin{tabular}{llrrrrrr}
\hline & \multicolumn{3}{c}{ Full sample } & \multicolumn{3}{c}{ From 1920 } \\
\hline & & Coeff. & Std.err. & T-stat & Coeff. & Std.Err. & T-stat \\
\hline TVARFIMA & $d_{R}$ & 0.462 & 0.079 & 5.841 & 0.304 & 0.041 & 7.427 \\
& $d_{E}$ & 0.274 & 0.038 & 7.242 & 0.241 & 0.027 & 8.863 \\
\hline TVFIGARCH & $\omega$ & 0.008 & 0.008 & 0.943 & 0.000 & 0.008 & 0.050 \\
& $\lambda_{R}$ & 0.269 & 0.025 & 10.854 & 0.241 & 0.018 & 13.117 \\
& $\lambda_{E}$ & 0.400 & 0.083 & 4.815 & 0.326 & 0.043 & 7.501 \\
\hline
\end{tabular}

Table 3: Estimation output for the full sample and restricted sample (from 1920). $R$ denotes recession coefficients and $E$ expansion coefficients.

while the memory coefficient in the mean equal 0.462 for recessions, it decreases to 0.274 in periods of expansion. Differently, the variance persistence moves from 0.269 in recessions up to 0.4 during expansions. This result is confirmed if we restrict the sample and consider data from 1920: in the mean, the memory coefficient decreases from 0.304 in recessions to 0.241 during expansions, while in the variance, the memory increases from 0.241 up to 0.326 . We believe this is a relevant finding, and is also supported by a Wald-type test for equality across memory coefficients. In that case the null hypothesis is $d_{E}=d_{R}$ and the test statistic equals 86.6 in the full sample and 133.7 from 1920. Note that the test statistic is assumed to be asymptotically distributed as a Chi-square with 1 degree of freedom, thus strongly rejecting the null.

The fact the persistence is higher in recession than expansions might be motivated by the fact that recessions are shorter and more clearly identifiable than expansion phases. A supporting evidence is given by the average duration of the business cycle phases: while for recessions we have 
an average duration of 16.5 months, for expansions the value increases up to 41.4 months. Further, during expansions, we might have oscillations in the growth cycle that could affect the persistence. In addition, another line of reasoning could be that, while in our model we have two states, in reality we might have also stagnation and this is, in our analyses, associated with expansion and hence, could affect the persistence during expansion. As an aside, we also show that persistence of inflation volatility is higher in expansions than recessions. This is somewhat expected, as it implies that volatility persists on a low regimes during expansions, while we have a larger uncertainty and a large reaction to shocks during recessions (less persistence induce a larger reaction of volatility to innovations). The findings are substantially confirmed on the shorter period.

We note that the estimated models have a very simple structure, combining state-dependent memory coefficients with intercepts. We verified by means of standard approaches the presence of residual serial correlation, both in the mean and in the variance. Despite some mild evidences of residual serial correlation in the mean, associated with lag 4 (which has no economic intuition), alternative model specifications with different orders of both short memory AR and MA polynomials always provided non significant coefficients and residuals with the same mild findings of serial correlation. Moreover, we also checked for residual heteroskedasticity, without any evidence. As a final check, we also consider alternative GARCH-type models with short-memory only. The results were, overall, 
inferior to those of the TVFIGARCH specification.

\section{Concluding remarks}

Given that the degree of inflation persistence determines the extent to which central banks can control inflation, the persistence property of inflation is an important issue. Also, not only is the level of inflation persistence that is important in economic analyses, but also the question of whether the persistence varies over time, for instance, across business cycle phases, is equally pertinent. This is understandable since, assuming constant persistence across expansionary and contractionary states of the economy, is sure to lead to misguided policy decisions. Against this backdrop, we extend the literature on long-memory models of inflation persistence for the US economy over the monthly period of 1876:2-2014:5, by developing an autoregressive fractionally integrated moving average-generalized autoregressive conditional heteroskedastic (ARFIMA-GARCH) model, with a time-varying memory coefficient which varies across expansions and recessions. In sum, we find that, inflation persistence does vary across recessions and expansions, with it being significantly higher in the former than in the latter. As an aside, we also show that, persistence of inflation volatility however, is higher during expansions than in recessions. Understandably, our results imply that the policy stance of the Federal Reserve should be asymmetric, depending on not only what is the main concern 
of the Federal Reserve, i.e., level or volatility of inflation, but also whether the economy is in recession or expansion. More importantly, our results also imply that Federal Reserve faces a trade-off, in terms of policy decision that it takes on the interest rate-setting, depending on its attempt to control the level or volatility of the inflation rate.

\section{References}

Ajmi, A. N., Nasr, A. B., and Boutahar, M., 2008, Seasonal nonlinear long memory model for the US inflation rates, Computational Economics, 31(3), 243-254.

Aloy M., Tong C-L., Péguin-Feissolle A., and Dufrénot, G., 2013, A smooth transition long-memory model, Studies in Nonlinear Dynamics \& Econometrics, 17(3), 281-296.

Baillie, R. T., Chung, C.F., and Tieslau, M. A., 1996, Analysing inflation by the fractionally integrated ARFIMA-GARCH model, Journal of Applied Econometrics, 11, 2340.

Baillie, R. T., Han, Y. W., and Kwon, T. G., 2002, Further long memory properties of inflationary shocks, Southern Economic Journal, 496-510. 
Balcilar M., Gupta R., and Jooste, C., 2014. Analysing South Africa's inflation persistence using an ARFIMA model with Markov-switching fractional differencing parameter, Working paper 2014-40, Department of Economics, University of Pretoria. Available: http://web.up.ac.za/sitefiles/ file/40/677/WP 2014_40.pdf.

Ball, L., Cecchetti, S. G., and Gordon, R. J., 1990, Inflation and uncertainty at short and long horizons, Brookings Papers on Economic Activity, 215-254.

Barsky, R. B., 1987, The Fisher hypothesis and the forecastability and persistence of inflation, Journal of Monetary Economics, 19(1), 3-24.

Baum, C. F., Barkoulas, J. T., and Caglayan, M., 1999, Persistence in international inflation rates, Southern Economic Journal, 900-913.

Bos, C., Franses, P. H., and Ooms, M., 1999, Re-analyzing inflation rates: Evidence of long memory and level shifts, Empirical Economics, 24,427449 .

Boutahar, M., Dufrénot, G., and Pguin-Feissolle, A., 2008, A simple fractionally integrated model with a time-varying long memory parameter $d_{t}$, Computational Economics, 31(3), 225-241. 
Brunner, A. D., and Hess, G. D., 1993, Are higher levels of inflation less predictable? A state-dependent conditional heteroscedasticity approach, Journal of Business and Economic Statistics, 11(2), 187-197.

Caporin M., and Pres, J., 2009. Forecasting temperature indices with time-varying long-memory models. Working paper 88-2009. Department of Economics and Management, University of Padua. Available: http:/ /www. decon.unipd.it/assets/ pdf/wp/20090088. pdf.

Caporin, M., and Pres, J., 2013, Forecasting Temperature Indices Density with Time-Varying Long-Memory Models, Journal of Forecasting, 32, 339-352.

Diebold, F.X and Inoue, A., 2001, Long memory and regime switching, Journal of Econometrics, 105, 131-159.

Goldman, E., Nam, J., Tsurumi, H., and Wang, J., 2013, Regimes and long memory in realized volatility, Studies in Nonlinear Dynamic and Econometrics, 17(5), 521-549.

Granger, C.W.J., and Hyung, N., 2000, Occasional Structural Breaks and Long Memory, revised version of UCSD Working Paper 99-14.

Haldrup, N., and Nielsen, M.O., 2006a, A regime switching long mem- 
ory model for electricity prices, Journal of Econometrics, 135, 349-376.

Haldrup, N., and Nielsen, M.O., 2006b, Directional congestion and regime switching in a long memory model for electricity prices, Studies in Nonlinear Dynamics and Econometrics, 10, 1367.

Hassler, U., and Meller, B., 2014, Detecting multiple breaks in long memory the case of US inflation, Empirical Economics, 46(2), 653-680.

Hassler, U., and Wolters, J.,1995, Long memory in inflation rates: International evidence, Journal of Business and Economic Statistics, 13, 37-45.

Hsu, C. C., 2005, Long memory or structural changes: An empirical examination on inflation rates, Economics Letters, 88, 289294.

Lee, J., 2005, Estimating memory parameter in the US inflation rate, Economics Letters, 87, 207210.

Manzan, S., and Zerom, D., forthcoming, Asymmetric quantile persistence and predictability: the case of U.S. inflation, Oxford Bulletin of Economics and Statistics.

Martins, L. F., and Rodrigues, P. M. M., 2014, Testing for persistence 
change in fractionally integrated models: An application to world inflation rates, Computational Statistics and Data Analysis, vol. 76, 502-522.

Mikosch, T., and Starica, C., 2004, Change of structure in financial time series, long range dependence and the GARCH models, Econometrics, EconWPA 0412004.

Nelson, C. R., and Schwert, G. W., 1977, Short-term interest rates as predictors of inflation: On testing the hypothesis that the real rate of interest is constant, The American Economic Review, 67(3), 478-486.

Tillmann, P., and Wolters, M. H., 2014, The changing dynamics of US inflation persistence: a quantile regression approach, Kiel Working Paper No. 1951.

Tsay, W. J., and Härdle, W. K., 2009, A generalized ARFIMA process with Markov-switching fractional differencing parameter, Journal of Statistical Computation and Simulation, 79(5), 731-745.

Tsay, W.J. 2008. Analysing inflation by the ARFIMA model with Markovswitching fractional differencing parameter, Mimeo, The Institute of Economics, Academia Sinica, Taiwan. Available at: http://idv.sinica.edu.tw/ wjtsay/pdf/example.pdf. 


\section{A Additional figure}

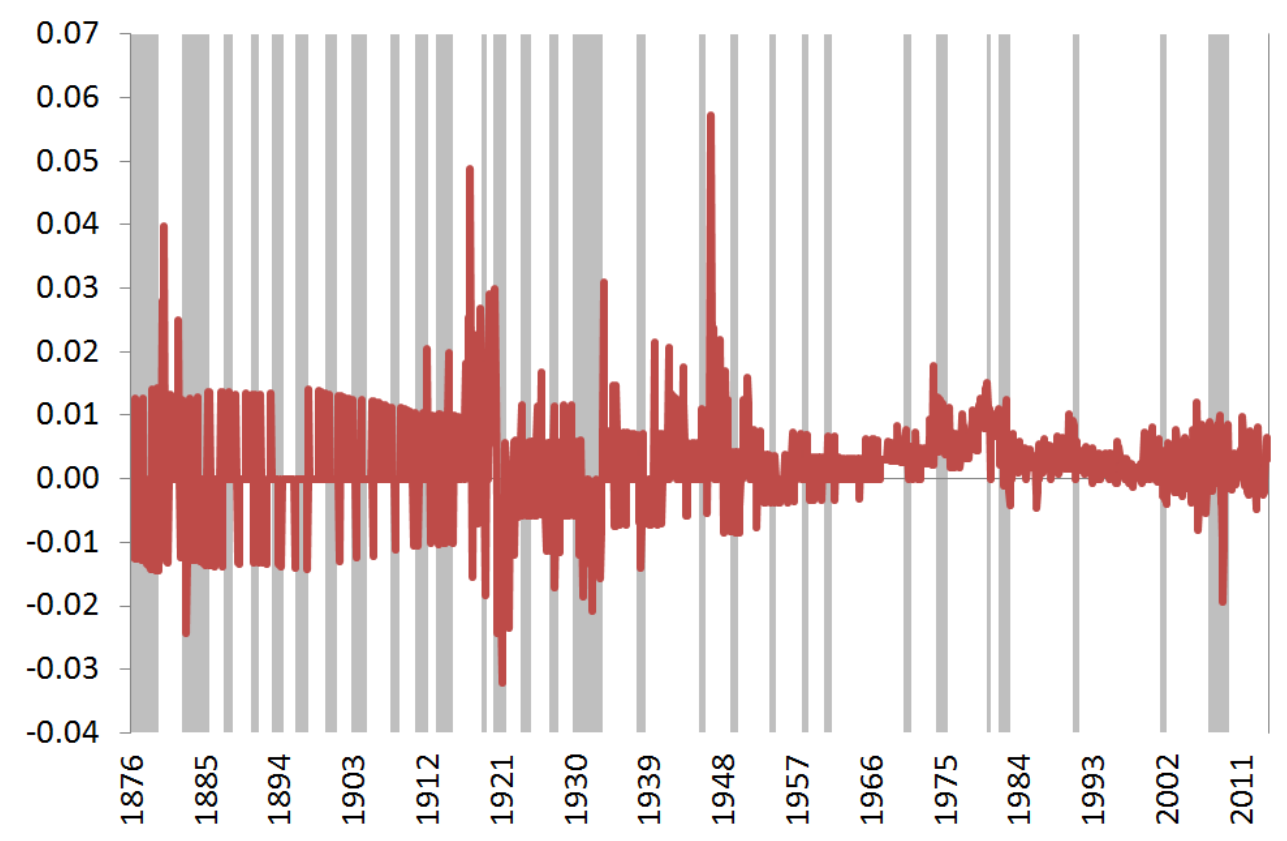

Figure A.1: Month-on-month US inflation from 1876:1 to 2014:5. 